\title{
Role of modified biophysical profile and cerebroplacental ratio in fetal outcome in low risk and high risk pregnancies
}

\author{
Urvashi, Sujani B. K., Krishna Sai Sushma*
}

Department of Obstetrics and Gynecology, M. S. Ramaiah Medical College, Bengaluru, Karnataka, India

Received: 09 January 2018

Accepted: 03 February 2018

\section{*Correspondence:}

Dr. Urvashi,

E-mail: drurvashi0701@gmail.com

Copyright: (C) the author(s), publisher and licensee Medip Academy. This is an open-access article distributed under the terms of the Creative Commons Attribution Non-Commercial License, which permits unrestricted non-commercial use, distribution, and reproduction in any medium, provided the original work is properly cited.

\begin{abstract}
Background: The timely detection of morbid changes in the fetal status followed by adequate interventions to avoid death or disability is one of the most important objectives of prenatal care. Objective of present study was to Comparing the role of modified biophysical profile and the cerebroplacental ratio in fetal outcome in low risk and high risk pregnancies.

Methods: Two hundred and seventy three singleton pregnant women were included in this study. Following routine examination, amniotic fluid index, pulsatility index of middle cerebral artery and pulsatility index of umbilical artery, uterine artery mean pulsatility index were evaluated. Non stress test (NST) was done. Modified biophysical profile (MBPP) and Cerebroplacental ratio (CPR in percentile) was generated. Caeserean section because of Fetal distress, birth weight $<10$ th centile, $5 \mathrm{~min}$ APGAR $<7$, NICU stay $>24$ hours were used in evaluating the perinatal outcome.

Results: Out of 273 cases, 107 cases had poor perinatal outcome. Out of 107 cases, $35.5 \%$ cases were IUGR, 39.2\% cases underwent caesarean section in view of fetal distress, 39.2\% babies had 5min APGAR $<7$ and $32.7 \%$ babies had stayed in NICU for $>24 \mathrm{hrs}$. In high risk cases, poor perinatal outcome was seen in $45.5 \%$ pregnancies and $36.7 \%$ in low risk pregnancies. Sixty seven percent of these cases had abnormal modified biophysical profile and only $7.4 \%$ cases had cerebroplacental ratio $<1$.

Conclusions: Modified biophysical profile was proved to be more significant than cerebroplacental ratio in prediction of perinatal outcome.
\end{abstract}

Keywords: Cerebroplacental ratio, Modified biophysical profile, Perinatal outcome

\section{INTRODUCTION}

The timely detection of morbid changes in the fetal status followed by adequate interventions to avoid death or disability is one of the most important objectives of prenatal care. ${ }^{1}$ The main techniques for fetal assessment are the nonstress test, biophysical profile, modified biophysical profile, contraction stress test, and fetal movement count. Assessment of amniotic fluid volume and Doppler velocimetry provide additional information about fetal status. Modified Biophysical profile is one of the available tests for primary fetal surveillance. It combines the observation of an index of acute fetal hypoxia - the Non Stress test and an indicator of chronic fetal problem amniotic fluid volume. ${ }^{2}$ Non stress test (NST) is most commonly used for antepartum evaluation of foetal status. It is easy, non-invasive, easily performed and interpreted method by which can identify nearly twice as many foetuses with an abnormal foetal heart rate pattern than intermittent auscultation of foetal heart rate. ${ }^{3}$ As NST can give rise to high false positive cases, addition of other 4 components of BPP helps to resolve that situation. The use of Doppler ultrasonography for the evaluation of the foetal circulation is based on physical principal i.e. the frequency of sound wave change when reflected from a moving object and proportional to the 
velocity of moving object (Doppler effect). ${ }^{4}$ Doppler ultrasound tests such as cerebroplacental ratio evaluation are commonly used nowadays, and enable one to assess blood flow disturbances in placentoumbilical and fetocerebral circulations. The cerebroplacental ratio evaluation is used to detect and assess the fetal response to oxygen deficiency in utero. None of the tests for fetal surveillance are absolutely specific and interventions due to false positive test may lead to iatrogenic preterm delivery and increased neonatal morbidity. Present study is to know the role of modified biophysical profile and cerebroplacental ratio in fetal outcome in low risk and high risk pregnancies.

\section{METHODS}

This retrospective study was carried out in patients attending obstetrics outpatient and inpatient department at M S Ramaiah medical college and hospital, Bengaluru, Karnataka, during the period of January 2017 to September 2017. Two hundred and seventy three singleton pregnant women with gestational age between 32- 41 weeks were included in this study. Both high risk and low risk cases were included. Following routine examination, amniotic fluid index, middle cerebral artery and umbilical artery Doppler indices were evaluated. Nonstress test (NST) was done. Growth scan and Cerebroplacental ratio done between 28-36 weeks and done earlier depending upon risk. Only the last antenatal test within 7 days of delivery was considered for analysis. Modified biophysical profile and cerebroplacental ratio was generated. Caeserean section because of Fetal distress, birth weight <10th centile, 5min APGAR <7, NICU stay >24hours were used in evaluating the perinatal outcome. Frequency tables were prepared and percentage was calculated. Analysis was done using MS Excel and SPSS version 15.

\section{RESULTS}

Out of 273 singleton pregnancies studied, 196 (71.8\%) were low risk cases and 77(28.2\%) cases were high risk pregnancies.

Table 1: Maternal characteristics in high risk and low risk pregnancies.

\begin{tabular}{|lll|}
\hline Age & $\begin{array}{l}\text { High risk group } \\
(77) \mathrm{N}(\%)\end{array}$ & $\begin{array}{l}\text { Low risk group } \\
(196) \mathrm{N}(\%)\end{array}$ \\
\hline$\leq 19 y e a r s$ & $5(6.4 \%)$ & $6(3.06 \%)$ \\
\hline 20-29years & $63(81.8 \%)$ & $171(87.24 \%)$ \\
\hline $\begin{array}{l}\geq 30 y e a r s \\
\text { Parity }\end{array}$ & $9(11.6 \%)$ & $19(9.6 \%)$ \\
\hline Primipara & $38(49.3 \%)$ & $111(56.6 \%)$ \\
\hline Multipara & $39(50.7 \%)$ & $85(43.36 \%)$ \\
\hline Gestational age & & \\
\hline$<34$ weeks & $8(10.3 \%)$ & $2(1.02 \%)$ \\
\hline 34-37 weeks & $20(25.97 \%)$ & $9(4.5 \%)$ \\
\hline$>37$ weeks & $49(63.63 \%)$ & $185(94.4 \%)$ \\
\hline
\end{tabular}

Maternal characteristics in high risk and low risk pregnancies are shown in Table 1 and neonatal characteristics in Table 2.

Table 2: Neonatal characteristics in high risk and low risk pregnancies.

\begin{tabular}{|lll|}
\hline $\begin{array}{l}\text { C-Section (fetal } \\
\text { distress) }\end{array}$ & $13(16.8 \%)$ & $25(12.7 \%)$ \\
\hline $\begin{array}{l}\text { Birth weight } \\
<10^{\text {th }} \text { centile }\end{array}$ & $15(19.4 \%)$ & $27(13.7 \%)$ \\
\hline $\begin{array}{l}\text { APGAR }<7 \text { at } \\
\text { 5mins }\end{array}$ & $8(10.3 \%)$ & $34(17.3 \%)$ \\
$\begin{array}{l}\text { NICU stay } \\
>24 h r s\end{array}$ & $17(22.07 \%)$ & $18(9.1 \%)$ \\
\hline
\end{tabular}

In high risk group, $6.4 \%$ of cases were $\leq 19 \mathrm{yrs}, 81.8 \%$ were $20-29 y r s$ age group and $11.6 \%$ were aged $\geq 30 y r s$. In low risk group, $3.06 \%, 87.2 \%$ and $9.6 \%$ were aged $\leq 19 \mathrm{yrs}, 20-29 \mathrm{yrs}$ and $\geq 30 \mathrm{yrs}$ respectively. In high risk group, $49.3 \%$ of primipara and $50.7 \%$ of multiparous were observed, whereas in low risk, $56.6 \%$ and $43.36 \%$ was observed respectively.

In high risk group, 49 pregnant women had gestational age $>37$ weeks and 20 women had $34-37$ weeks and 8 cases were <34weeks. In low risk group, 185 cases had $>37$ weeks gestational age, 9 cases were 34-37weeks and 2 cases had $<34$ weeks POG.

$16.8 \%$ (13) of cases underwent LSCS because of fetal distress in high risk group and $12.7 \%$ (25) in low risk group. In high risk, $19.4 \%$ (15) of IUGR cases were seen and $13.7 \%$ (27) cases in low risk.

In high risk, APGAR of $<7$ at $5 \mathrm{~min}$ seen in $10.3 \%$ (8) and $22.07 \%$ (17) of babies had NICU stay $>24$ hours. In low risk, APGAR $<7$ at 5mins seen in $17.3 \%$ (34) of cases and $9.1 \%$ (18) of babies had NICU stay $>24$ hours.

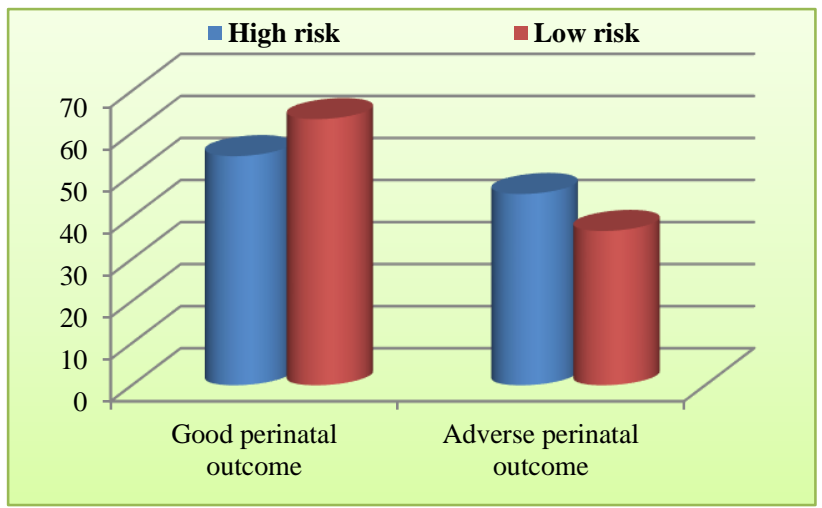

Figure 1: Perinatal outcome in high risk and low risk groups.

Out of 273 cases, $107(39.1 \%)$ cases had adverse perinatal outcome and $166(60.9 \%)$ cases had good 
perinatal outcome. $45.5 \%$ cases of high risk pregnancies and $36.7 \%$ cases of low risk pregnancies had adverse perinatal outcome (Figure 1).
In 273 pregnancies, 87 cases (31.8\%) had abnormal modified biophysical profile (MBPP) and 10 cases $(3.6 \%)$ had cerebroplacental ratio $(\mathrm{CPR})<1$.

Table 3: Modified biophysical profile and cerebroplacental ratio in adverse perinatal outcome cases.

\begin{tabular}{lllll}
\hline & & High risk group & Low risk group & Total \\
MBPP for 107 adverse & Normal MBPP & $9(25.7 \%)$ & $26(36.1 \%)$ & $35(32.7 \%)$ \\
perinatal outcome cases & Abnormal MBPP & $26(74.2 \%)$ & $46(63.9 \%)$ & $72(67.3 \%)$ \\
$\begin{array}{llll}\text { CPR for } 107 \text { adverse perinatal } \\
\text { outcome cases }\end{array}$ & Normal CPR & $32(91.4 \%)$ & $67(93 \%)$ & $99(92.5 \%)$ \\
\cline { 2 - 6 } & Abnormal CPR & $3(8.6 \%)$ & $5(7 \%)$ & $8(7.5 \%)$ \\
\hline
\end{tabular}

Table 4: Perinatal outcome and fetal assessment.

\begin{tabular}{|lll|} 
& $\begin{array}{l}\text { Poor perinatal } \\
\text { outcome (107) }\end{array}$ & $\begin{array}{l}\text { Good perinatal } \\
\text { outcome (166) }\end{array}$ \\
\hline Abnormal MBPP & 72 & 15 \\
\hline Normal MBPP & 35 & 151 \\
\hline Abnormal CPR & 8 & 2 \\
\hline Normal CPR & 99 & 164 \\
\hline
\end{tabular}

In 107 cases of poor perinatal outcome, 72 cases had abnormal MBPP whereas only 8 cases had abnormal
CPR. In 166 cases of good perinatal outcome, 15 cases had poor perinatal outcome and 2 cases had abnormal CPR.

Sensitivity and specificity of MBPP was $67.2 \%$ and $90.9 \%$ respectively. Sensitivity of CPR was $7.48 \%$ and specificity being $98 \%$.

PPV of MBPP and CPR was $82.7 \%$ and $80 \%$, respectively and NPV was $81.1 \%$ and $62.3 \%$ respectively. (Table 5).

Table 5: Predictive value of detecting abnormal fetal outcome.

\begin{tabular}{|lllll|} 
& Sensitivity & Specificity & Positive predictive value & Negative predictive value \\
\hline MBPP & $67.2 \%$ & $90.9 \%$ & $82.7 \%$ & $81.18 \%$ \\
\hline CPR & $7.48 \%$ & $98 \%$ & $80 \%$ & $62.3 \%$ \\
\hline
\end{tabular}

\section{DISCUSSION}

In this study, more number of pregnancies with age $\leq 19$ years was observed in high risk pregnancies. Pregnancies in age group between 20-29 years and $\geq 30$ years were equal in distribution in both high risk and low risk groups (Table 1). There was higher number of preterm deliveries in high risk group than in low risk group (Table 1).

Most of the preterm deliveries were because of induction of labour in patients with abnormal MBPP, to prevent fetal hypoxia.

Majority of IUGR cases were observed in high risk group, reason being most of the pregnancies in high risk group were complicated by hypertensive disorders resulting fetal growth restriction (Table 2). Stay in NICU for more than $24 \mathrm{hrs}$ was seen in high risk group babies than in low risk, because of preterm deliveries and fetal growth restriction (Table 2).
Out of 107 adverse perinatal outcome cases, $45.5 \%$ cases were seen in high risk pregnancies and $36.7 \%$ cases in low risk pregnancies (Figure 1).

In these 107 cases, $67.3 \%$ cases had abnormal modified biophysical profile and $7.5 \%$ cases had cerebroplacental ratio $>1$ (Table 3 ).

Sensitivity of modified biophysical profile was $67.2 \%$, specificity was $90.9 \%$, positive predictive value was $82.7 \%$ and negative predictive value was $81.1 \%$, whereas sensitivity, specificity, positive predictive value (PPV) and negative predictive value (NPV) of CPR was $7.48 \%$, $98 \%, 80 \%$ and $62.3 \%$ respectively (Table 5 ).

A study done by Maurya A et al, sensitivity of MBPP in predicting fetal outcome was $79.5 \%$ and PPV was $85.83 \%$ which is corresponding to present study. ${ }^{2}$

Bardakci et al, observed that sensitivity of MBPP was $60 \%$ in predicting perinatal outcome and also stated that 
MBPP was more significant than doppler studies in predicting outcome. ${ }^{5}$

In a study by Gramalleni et al, CPR was calculated in high risk pregnancies only and they reported that sensivity, specificity, PPV, NPV as $68.0 \%$, 98.4\%, $94.4 \%$, and $88 \%$ respectively. ${ }^{6}$

Number of studies have suggested that the cerebroplacental ratio may be more sensitive in predicting neonatal outcome in pregnancies with placental insufficiency. ${ }^{7}$

In a study by Turan $\mathrm{S}$ et al, based on 58 pregnant patients, it was observed that instead of using individual methods combining 2 or more antenatal tests yielded much better results in sensitivity while evaluating fetal outcome. ${ }^{8}$

A study by DeVore GR, reported that the CPR is an earlier predictor of adverse outcome than the biophysical profile, umbilical artery, or middle cerebral artery, and the CPR should be considered as an assessment tool in fetuses undergoing third-trimester ultrasound examination, irrespective of the findings of the individual umbilical artery and middle cerebral artery measurements. ${ }^{9}$

Odibo et al stated that, an abnormal CPR is associated with adverse perinatal outcomes in growth-restricted fetuses. ${ }^{10}$ The accuracy of using gestational age-specific reference levels was similar to that of using a categorical threshold (1.08).

\section{CONCLUSION}

Modified biophysical profile was proved to be more significant than cerebroplacental ratio in prediction of perinatal outcome, though cerebroplacental ratio was earlier to become pathological (less than $5^{\text {th }}$ percentile) during the course of affection, in fetal growth restriction. However, the sensitivity in predicting perinatal outcome will be increased when both are combined. Modified BPP is cost effective, non-invasive and best screening test to evaluate fetal health and to predict fetal outcome. If Doppler is combined with BPP, those cases which had non-reassuring NST, may not end up in iatrogenic preterm while being monitored. Needs larger studies, before considering CPR for a routine antenatal fetal health surveillance. Further studies are needed whether Barcelona criteria to be followed or not in our Indian population.

Funding: No funding sources Conflict of interest: None declared Ethical approval: Not required

\section{REFERENCES}

1. Mehta N, Agarwal M, Beniwal D, Sharma A, Fayyaz S. Colour Doppler versus nonstress test as prediction of adverse perinatal outcomes in high risk pregnancies. IOSR-JDMS. 2016;15(12V):79-82.

2. Maurya A, Kushwah N. Modified biophysical profile and fetal outcome in high risk pregnancy. Sch J App Med Sci. 2014;2(1C):283-290

3. Arias F, Daftary SN, Bhide AG. Practical guide to high risk pregnancy and delivery:a South Asian Perspective. $3^{\text {rd }}$ ed. Elsevier India;2011:16-29.

4. Bhatt AB, Tank PD, Barmade KB, Damania KR. Abnormal Doppler flow velocimetry in growth retarded foetuses as a predictor of nectrotizing enterocolitis. J Postgraduate Med. 2003;48(3):145-8.

5. Bardakci M, Balci O, Acar A, Colacoqlu MC. Comparison of modified biophysical profile and Doppler ultrasound in predicting the perinatal outcome at or over 36 weeks of gestation. Gynecol Obstet Invest. 2010;69:245-50.

6. Gramellini D, Folli MC, Sacchini C, Sterbini MP, Lombardo A, Meriladi A. Fetal and maternal velocimetry in high risk pregnancies for the assessment of adverse perinatal outcome. Echocardiography. 1990; 7:597-601.

7. Arbeille P, Carles G, Chevillot M, Locatelli A, Herve $\mathrm{P}$, Perrotin F et al. Cerebral and umbilical Doppler in the prediction of fetal outcome. InDoppler Ultrasound in Obstetrics and Gynecology Springer, Berlin, Heidelberg;2005:177-197.

8. Turan S, Turan OM, Berg C, Mayona D, Bhide A, Bower S, et al. Computerized fetal heart rate analysis, Doppler ultrasound and biophysical profile score in the prediction of acid-base status of growthrestricted fetuses. Ultrasound Obstet Gynecol 2007;30:750-6.

9. DeVore GR. The importance of the cerebroplacental ratio in the evaluation of fetal well-being in SGA and AGA foetuses. Am J Obstet Gynecol. 2015;213:515.

10. Odibo AO, Riddick C, Pare E, Stamilio DM, Macones GA. Cerebroplacental Doppler ratio and adverse perinatal outcomes in intrauterine growth restriction: evaluating the impact of using gestational age-specific reference values. J Ultrasound Med. 2005 Sep;24(9):1223-8.

Cite this article as: Urvashi, Sujani BK, Sushma $\mathrm{KS}$. Role of modified biophysical profile and cerebroplacental ratio in fetal outcome in low risk and high risk pregnancies. Int J Reprod Contracept Obstet Gynecol 2018;7:1104-7. 